\title{
The heat transfer crisis in shear driven liquid film of FC-72 by gas flow in a minichannel
}

\author{
Vyacheslav Cheverda $^{1,2^{*}}$ \\ ${ }^{1}$ Institute of Thermophysics, SB RAS, Lavrentiev Prospect, 630090, Novosibirsk, Russia \\ ${ }^{2}$ Novosibirsk State University, Pirogova str. 2, 630090Novosibirsk, Russia
}

\begin{abstract}
The crisis in a FC-72 liquid film moving under the action of a gas flow through a smooth heater was experimentally investigated. It is shown that with gas and liquid flow rates increases a critical heat flux is growth.
\end{abstract}

\section{Introduction}

The rapid development of semiconductor technologies, including the reduction in the size of the transistor, that is, increasing their density, leads to higher heat fluxes and dissipated power from the chip surface. The forecast for high-performance chips suggests that the maximum power dissipation will exceed 500 watts $[1,2]$. Moreover, in recent years, the performance requirements have increased, which leads to greater heat flux from the chip and the occurrence of "hot spots", the heat flux in which often exceeds $1 \mathrm{~kW} / \mathrm{cm}^{2}$, which is danger for microprocessor. The two-phase flow is a promising solution of this problem [3$5]$.

The authors' studies in [6-9] were focused on underheated thin fluid films flowing down through a locally heated plate. Forced flow of dielectric liquids, with intense evaporation in the minichannel, is a promising solution for cooling modern semiconductor devices for terrestrial and space applications [10]. Fluid FC-72 is designed to cool the electronics and is volatile with low surface tension [11]. The destruction of liquid films on a heated wall is of great technical importance, since this determines the allowable heat flux in a number of engineering applications. A comparison between the flowing fluid film and the liquid film moving under the action of the gas flow is shown in $[12,13]$. Surface temperature, heat flux for formation of the first dry spot and critical heat flux are shown and analysed in the paper [12]. The critical heat flux is measured and shown, the liquid film moving under the action of the gas flow is up to five times more efficient than the flowing fluid film. It was found in the number of papers that the thermocapillary foresees play a crucial role in shear driven cooling systems of microelectronic devices [14 - 16].

\section{Experimental setup}

*Corresponding author: slava.cheverda@gmail.com 
The experiments were carried out using the experimental setup shown in (Fig.1). The setup includes: a system for supplying working fluids, a measuring system (sensors) and an optical (speed schlieren-system) system, a working fluid supply system, a data collection system and a remote-control system. The two temperature stabilization systems are based on the use of thermoelectric modules (Peltier elements) and are used to stabilize the temperature of the liquid and gas at the entrance to the work area. All thermal modules are cooled by a water circuit. The temperatures of liquid and gas at the inlet to the test cell are maintained between 10 and $30^{\circ} \mathrm{C}$. Dielectric fluid FC-72 and dry nitrogen gas are used as working fluids. The operating pressure and gas flow rate are automatically controlled by the Bronkhost flow and pressure regulators. Degassed liquid is fed into the working area with a syringe pump from a flexible liquid container. From the working area, a mixture of steam, gas and liquid is pumped into the atmosphere. All parameters are remotely controlled using a control and data acquisition system developed on the LabView platform.

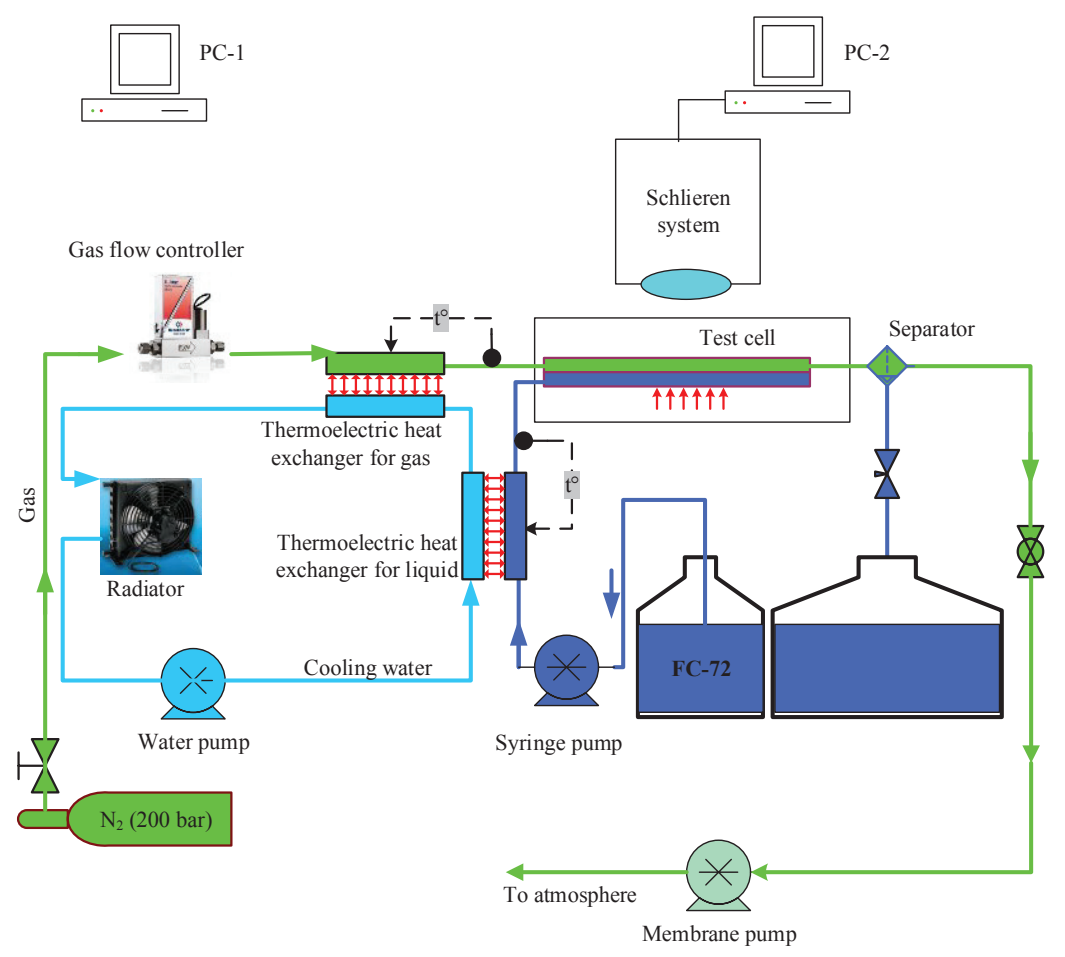

Fig. 1. Scheme of the experimental setup.

The experimental test cell (see Fig. 2) consists of: 1) a textolite plate, 2) stainless steel substrates with a copper pressed rod, 4) a liquid nozzle, 5) a textolite frame, and 6) a textolite cover with an optical window. The flow of the film is realized in the minichannel, using a liquid nozzle. The main element of the working area is a stainless-steel plate with a $10 \times 10 \mathrm{~mm}$ copper rod. Several calibrated K-type thermocouples are used to measure temperature. A stainless-steel plate is attached to a textolite plate together with a textolite frame. The frame with the plate is covered with a transparent window, forming a rectangular minichannel $67 \times 30 \times 1.4 \mathrm{~mm}$ (length, width and depth, respectively). Liquid film is formed with the help of a liquid nozzle and is carried along the channel by a gas stream. The temperatures of the substrate, as well as gas and liquid at the inlet and outlet of the working section, are measured with accuracy $0.4^{\circ} \mathrm{C}$. The power of the heater is regulated and controlled by a power source. 
The optical system makes it possible to visualize with great frequency and to measure the deformation angles of the gas-liquid interface. This system allows us to visualize at a frequency of up to $500 \mathrm{~Hz}$ for a full resolution of $1280 \times 1024$ pixels and up to $60 \mathrm{kHz}$ for a reduced resolution of $1280 \times 4$ pixels.

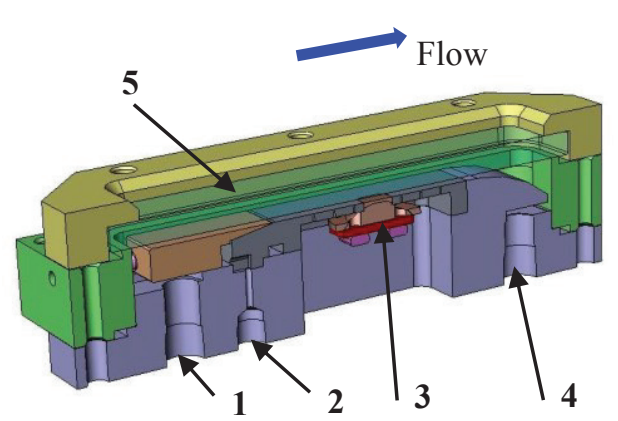

a) Scheme of the test cell

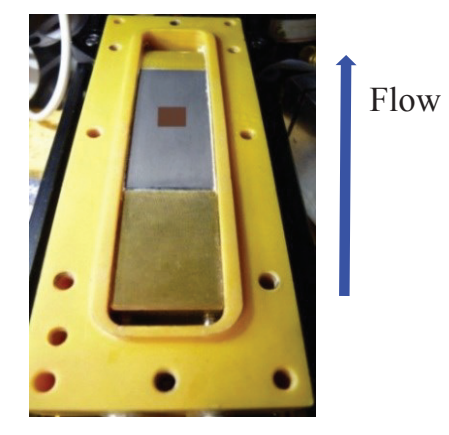

b) Photo of the test cell

Fig. 2. Scheme (a) and photo (b) of the test cell, 1 - gas inlet, 2 - liquid inlet, 3 - copper rod, 4 - two-phase outlet, 5 - optical window.

\section{Experimental results}

The development of crisis phenomena during the flow of a FC-72 film liquid under the action of a nitrogen gas flow is studding in details. When the heater is turned on all temperatures increase and deformations at the gas-liquid interface increase. With a further increase in the heat flux, formation of the first, unstable dry spots can be observed.

A dry spot forms near the right lower edge of the heating element due to the high temperature gradient at the gas-liquid interface. However, the heat flux is not high enough, and this first dry spot is moving from heater area. With increasing heat flux, the first stable dry spot appears. With a further increase in heat flux, the heater is practically not wetted by the liquid and the temperature of the heater slightly increases. At some point, the liquid begins to move around the heater and does not wet at all. All the temperatures of the heater and the substrate begin to increase with a relatively large gradient. In this case critical heat flux $\left(\mathrm{Q}_{\mathrm{CHF}}\right)$ is measured. The results of measurements of the critical heat fluxes in a FC-72 liquid film moving under the action of a nitrogen gas flow are shown in Fig. 3. It can be seen that the critical heat flux increases with increasing gas and liquid Reynolds numbers (Re_G, L). 


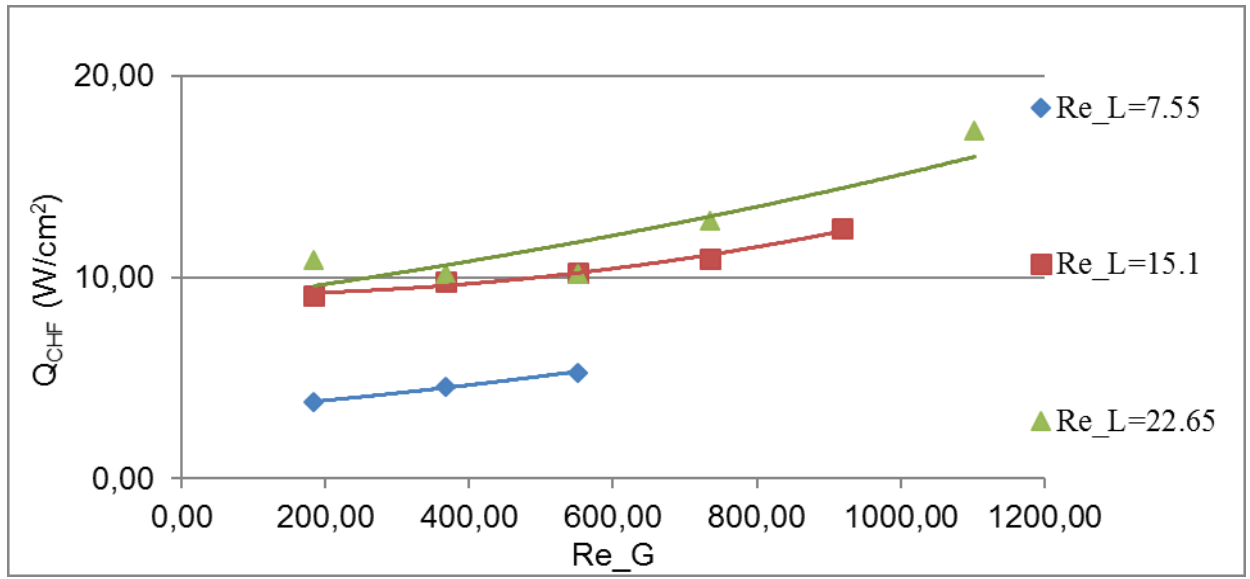

Fig. 3. The critical heat flux for shear driven FC-72 liquid film moving in a minichannel with smooth heater for different liquid and gas Reynolds numbers.

\section{Conclusion}

The work shows an increase of the critical heat flux for the FC-72 liquid film flow in a minichannel by a gas flow when using smooth heater when gas and liquid Reynolds number are increases. It is supposed that the dray patch formation and the crisis phenomenon are happening because of the strong thermocapillary effect. Thermocapillary foresees move liquid from the heater. The crisis phenomenon take place at temperatures of the gas-liquid interphase much smaller than the saturation temperature.

This study was performed in the framework of the Russian Ministry of Education (RFMEFI60414X0053).

\section{References}

1. Wang P., Bar-Cohen A., Yang B., Solbrekken G. L., Zhang Y. and Shakouri A., Proceedings of InterPACK '05, 73244 (2005).

2. Mahajan R., Chiu C., Chrysler G., Proc. IEEE, 94, 1476-1486 (2006).

3. Chinnov, E. A.; Ron'shin, F. V.; Kabov, O. A., Technical physics letters. 41, 817-819 (2015)

4. Chinnov, E. A.; Ron'shin, F. V.; Kabov, O. A., Thermophysics and aeromechanics. 22, 621-629 (2015)

5. Chinnov, E. A.; Ron'shin, F. V.; Kabov, O. A., Thermophysics and aeromechanics. 22, 265-284 (2015)

6. Kabov O.A., Thermophys. Aeromech. 7, 513-520 (2000)

7. Kabov O.A., Scheid B., Sharina I.A., Legros J.-C., Int. J. Thermal Sciences, 41, 664-672 (2002)

8. Chinnov E. A., Shatskii E. N, High temperature. 52, 461-464 (2014)

9. Chinnov E. A., Shatskiy E. N., Technical physics letter. 40, 7-9 (2014)

10. Bar-Cohen A., Rahim E., Heat Transfer Eng. 30, 601, (2009).

11. Ing P., Sperry R., Philstorm R., Claybacker P., Webster J. and Cress S., Proceedings of the 1993 IEEE ECTC Conference, 219-237 (1993).

12. Kabov O.A., Lyulin Yu.V, Marchuk I.V., Zaitsev D.V., Locally heated shear-driven liquid films in microchannels and minichannels, Int. J. Heat Fluid Flow, 28, 103-112 (2007) 
13. Kabov O.A., Zaitsev D.V., Cheverda V.V., Bar-Cohen A., Experimental Thermal and Fluid Science, 35, 825 (2011)

14. Hirokawa T., Murozono M., Kabov O. and Ohta H., Frontiers in Heat and Mass Transfer, 3, 1-8 (2014).

15. Hirokawa T., Ohta H. and Kabov O. A., Interfacial Phenomena and Heat Transfer, 3, 303-317 (2015).

16. Kabov O. A. and Kabova Yu. O., Thermophysics and Aeromechanics, 22, 539-542 (2015). 